\title{
O impacto da disfonia em professores: queixas vocais, procura por tratamento, comportamento, conhecimento sobre cuidados com a voz, e absenteísmo
}

\author{
Comentado por: Lhaís Renata Mestre ${ }^{1}$, Léslie Piccolotto Ferreira ${ }^{2}$
}

Van Houtte E, Claeys S, Wuyts F, Van Lierde K. The impact of voice disorders among teachers: vocal complaints, treatment-seeking behavior, knowledge of vocal care, and voice-related absenteeism. J Voice. $2010 \mathrm{Jul}$ 14. [Epub ahead of print]

Os autores iniciam o artigo esclarecendo que, dentre os profissionais da voz, os professores são os mais suscetíveis a terem alterações vocais. Apesar de belgas, percebe-se que essa realidade é semelhante à de uma série de outros países. Tal fato é comprovado, por exemplo, em pesquisas, que retratam a realidade entre americanos ${ }^{(1)}$ suíços $^{(2)}$ e espanhóis ${ }^{(3)}$, e também em nossa realidade ${ }^{(4)}$. A maior prevalência está certamente relacionada às características próprias dessa ocupação, que apresenta uma intensa e prolongada jornada de trabalho, realizada em ambientes ruidosos e em condições adversas quanto à organização do trabalho.

A proposta da pesquisa apresentada pelos autores foi investigar o impacto dos distúrbios da voz em professores, o conhecimento dos mesmos sobre a voz, o seu comportamento de busca pelo tratamento e o absenteísmo relacionado à voz. Participaram dessa pesquisa 994 professores, que foram comparados a um grupo controle de 290 participantes cujo trabalho não envolvia esforço vocal. Todos os participantes preencheram um questionário abordando a presença de queixas vocais, tratamento, e ausências relacionadas à voz, além de perguntas relacionadas aos cuidados com a mesma. É importante destacar que, também em nossa realidade, é comum a realização de pesquisas com a utilização de questionários ${ }^{(4)}$, sendo esse instrumento importante para levantamentos iniciais de determinados aspectos e muitas vezes útil para o diagnóstico, antes de propor ações de promoção de saúde ou prevenção de alterações de voz.

No artigo belga, parte dos professores $(25,4 \%)$ procurou atendimento médico e 20,6\% tinham perdido pelo menos um dia de trabalho. Em nossa realidade, cada vez mais os dados indicam que os distúrbios psíquicos e vocais são as principais causas de afastamento do trabalho docente. Entre as profissões dos servidores municipais de São Paulo(5) ${ }^{(5)}$ por exemplo, há distribuição irregular de licenças médicas e readaptações funcionais por distúrbios da voz, uma vez que $97 \%$ das readaptações e $62 \%$ das licenças são concentradas em profissões

(1) Programa de Pós-graduação (Mestrado) em Voz, Pontifícia Universidade Católica de São Paulo - PUC-SP - São Paulo (SP), Brasil.

(2) Pontifícia Universidade Católica de São Paulo - PUC-SP - São Paulo (SP), Brasil.

Endereço para correspondência: Lhaís Renata Mestre. R. Martinópolis, 83, Vl. Pompéia, Campinas (SP), Brasil, CEP: 13050-471. E-mail: lhaismestre@hotmail.com relacionadas ao ensino, como professor, educador de creche e coordenador pedagógico.

$\mathrm{Na}$ pesquisa, ora resenhada, as mulheres mostraram-se mais propensas a ficar em casa $\left(\chi^{2}=7.10, \mathrm{df}=1, \mathrm{p}=0,008\right)$ e a procurar ajuda médica $\left(\chi^{2}=7.24, \mathrm{df}=1, \mathrm{p}=0,007\right)$, em comparação com seus colegas do sexo oposto. Os autores associaram a pouca procura por serviços de saúde pela dificuldade dos homens em adotar práticas de auto-cuidado pois, à medida que tal sexo é visto como viril, invulnerável e forte, procurar o serviço de saúde, numa perspectiva preventiva, poderia associá-lo à fraqueza, medo e insegurança. A ausência de procura pode acontecer também pelo medo da descoberta de uma doença grave ou mesmo a vergonha da exposição do corpo perante o profissional de saúde ${ }^{(6)}$. Os achados do artigo evidenciam que apenas 13,5\% de todos os professores receberam informações durante a graduação, porcentagem próxima à de pesquisa desenvolvida no Brasil ${ }^{(7)}$, em que, dentre os 149 professores entrevistados, 18,79\% responderam afirmativamente a mesma questão.

Os autores citam que os professores, por serem mais predispostos à afonia, edema, pólipos e nódulos, contribuem para a piora na qualidade do ensino e o aumento de ausências no trabalho. Outros fatores foram considerados de risco para esses educadores como: longo tempo de atividade docente, alto índice de alunos em sala, salas de aula com acústica ruim (o que induz o professor a falar mais alto e, portanto, com mais chance de vir a ter um distúrbio de voz). Outras condições desfavoráveis apontadas foram: ar seco, poeira, fumaça, mudanças de temperatura que podem irritar a mucosa e afetar negativamente a voz, fatores psicoemocionais e estresse. Resultados semelhantes foram encontrados em pesquisas brasileiras e dentre elas pode-se citar a proposta ${ }^{(8)}$ que analisou 128 professores e, desses, 54,7\% consideraram o local de trabalho nada ou pouco saudável e citaram salas quentes, mal ventiladas, com presença de poeira, sujeira, pó de giz, ruído interno e externo, além de problemas na organização do trabalho, com relações sociais estressantes, permeadas por sentimentos negativos como agressividade, indisciplina, desrespeito e violência. Tais condições, adversas à saúde geral e vocal, predispõem o sujeito a irritações laríngeas, competição sonora e uso abusivo ou inadequado da voz, que ocasionam alterações vocais, dados esses que vão na mesma direção dos autores belgas.

Os autores apontam poucos estudos referentes à investi- 
gação de professores que tiram licenças ou mesmo faltam ao trabalho por estarem com alterações vocais e inaptos a dar aula. Em levantamento realizado pelo Departamento de Saúde do trabalhador (DESAT) da Prefeitura de São Paulo constatou-se que houve um aumento significativo de $62 \%$ de licenças médicas entre o ano de 1999 a $2002^{(9)}$. No Brasil, os afastamentos por adoecimento vocal causam um prejuízo estimado em mais de 100 milhões de reais ao ano ${ }^{(10)}$. Apesar de vultoso, o valor referido pode ainda estar subestimado, pois há estimativa de afastamentos, licenças e readaptações por disfonia na ordem de $2 \%$ dos professores ativos ${ }^{(10)}$.

Ao finalizar este artigo pode-se destacar que os autores concluíram que os distúrbios da voz têm um impacto sobre a vida de professores tanto no âmbito profissional como pessoal, o que implica em um grande encargo financeiro para a sociedade, pois os professores faltam por estarem doentes, e com isso a sociedade sai perdendo, uma vez que isso representa um professor a menos em sala de aula e um gasto a mais para o governo. Um número significativo de professores precisou de ajuda médica, os que procuraram tratamento perderam um dia de trabalho e os que desistiram foram obrigados a ficar em casa devido às alterações de voz. É importante destacar que, se alguns faltam, muitos professores, mesmo adoentados, ainda trabalham, para darem conta de suas atribuições. Esse fenômeno, denominado de presenteismo, ou seja, estar presente no trabalho, mesmo doente, determina sintomas como dores de cabeça e nas costas, asma, alergias, irritação, pressão alta, alterações gastrintestinais, artrite e depressão ${ }^{(11)}$, aumentando, consequentemente, a possibilidade de distúrbio de voz.

Com dados semelhantes à nossa realidade, não foi surpresa ler ao final do artigo que, da mesma forma que ocorre na maioria dos nossos trabalhos, a recomendação sobre a implementação da educação vocal durante a formação dos professores, para preparar os mesmos a utilizar a voz de maneira adequada.

\section{REFERÊNCIAS}

1. Roy N, Merril RM, Thibeault S, Gray SD, Smith E. Voice-related work disruption in teachers and the general population. In: Simpósio Internacional do Centro de Estudos da Voz. A Voz Do Professor. Anais. São Paulo; 2006. p. 7-9.

2. Munier C, Kinsella R. The prevalence and impact of voice problems in primary school teachers. Occup Med. 2008; 58(1):74-6.

3. Acedo F. Aumentan los problemas de la voz a causa de los entornos ruidosos. [Internet]. Noticias de Salud,Espanha,18 de abril 2009. [citado 2010 Set 15]. Disponível em: http://noticiadesalud.blogspot. com/2009/04/aumentan-los-problemas-de-la-voz-causa.html

4. Dragone MLS, Ferreira LP,Giannini SP, Simões-Zenari M,Vieira VP, Behlau M. Voz do professor: uma revisão de 15 anos de contribuição fonoaudiológica. Rev Soc Bras Fonoaudiol. 2010;15(2):289-96.

5. Carneiro SAM. Saúde do trabalhador público: questão para a gestão de pessoas - a experiência na Prefeitura de São Paulo. Rev Serv Público. 2006; 57(1): 23-49.

6. Gomes R,Nascimento EF,Araújo FC. Por que os homens buscam menos os serviços de saúde do que as mulheres? As explicações de homens com baixa escolaridade e homens com ensino superior Cad Saúde Pública. 2007.23(3):565-74.
7. Quintanilha JK. Caracteristicas vocais de uma amostra da secretaria de estado de educação do Distrito Federal [dissertação]. Brasilia (DF): Universidade de Brasilia. 2006.p.1-101.

8. Penteado RZ, Pereira IM. Qualidade de vida e saúde vocal de professores. Rev Saúde Pública. 2007; 42(2):236-43.

9. Centro de Referência de Saúde do Trabalhador. CEREST-SP. Secretaria de Estado de Saúde de São Paulo. Distúrbios da voz relacionados ao trabalho. Bol Epidemiol Paul. 2006; 3(26):16-22.

10. Voz e trabalho: uma questão de saúde e direito do trabalhador. Rio de Janeiro: Academia Brasileira de Laringologia e Voz: Associação Brasileira de Otorrinolaringologia e Cirurgia Cérvio-Facial; 2004. In: $3^{\circ}$ Consenso Nacional sobre Voz Profissional; 2004.

11. Paschoalino JB. Professor adoecido entre o absenteísmo e o presenteísmo. In: VII Seminário Redestrado-Nuevas regulaciones em América Latina Buenos Aires, 3, 4 y 5 de Julio de 2008 [Internet]. [citado 2010 Nov 20]. Disponível em: htttp://www.fae.ufmg.br/estrado/ cdrom_seminario_2008/textos/trabajos 